\title{
Diretrizes de operação, manutenção e tratamento de dados em um moinho de bolas em
} escala laboratorial

\author{
Guidelines for operation, maintenance and data processing in a laboratory scale ball mill \\ Directrices para la operación, mantenimiento y procesamiento de datos em un molino de bolas a \\ escala de laboratorio
}

Recebido: 21/06/2021 | Revisado: 28/06/2021 | Aceito: 30/06/2021 | Publicado: 13/07/2021

Bruno Costa Rocha

ORCID: https://orcid.org/0000-0003-0281-0421 Universidade Federal do Triângulo Mineiro, Brasil E-mail: rocha1bruno@gmail.com

Davi Leonardo de Souza

ORCID: https://orcid.org/0000-0002-1995-9057 Universidade Federal do Triângulo Mineiro, Brasil E-mail: davi.souza@uftm.edu.br

\begin{abstract}
Resumo
O moinho de bolas é um importante equipamento de fragmentação que está presente no cotidiano e em diversas áreas desde a alimentícia até a mineral. O objetivo deste trabalho é apresentar práticas de como manusear e conservar um moinho de bolas em escala laboratorial, apresentar um modelo de prática experimental para a determinação do índice de trabalho em minérios e por fim maneiras de como adequar o produto obtido de moagem á dois modelos de distribuição granulométrica tendo como base um experimento executado no equipamento de estudo. As orientações para a utilização do equipamento e o procedimento experimental são coerentes com a literatura e de possível execução, os resultados dos modelos de granulometria são comparáveis sendo o modelo GGS o que melhor representa a produto granulométrico obtido.
\end{abstract}

Palavras-chave: Moinho de bolas; Operação do equipamento; Índice de trabalho; Análise granulométrica.

\begin{abstract}
The ball mill is an important fragmentation equipment that is present in everyday life and in various areas from food to mineral. The objective of this work is to present practices on how to handle and maintain a ball mill on a laboratory scale, present an experimental practice model for determining the work index in ores and finally ways to adapt the product obtained from grinding to two models of particle size distribution based on an experiment performed on the study equipment. The guidelines for the use of the equipment and the experimental procedure are consistent with the literature and easy execution, the results of the particle size models are comparable with the GGS model being the one that best represent the particle size product obtained.
\end{abstract}

Keywords: Ball mil; Equipment operation; Work index; Granulometric analysis.

\section{Resumen}

El molino de bolas es un importante equipo de fragmentación que está presente em la vida cotidiana y em diversas áreas desde la alimentación hasta el mineral. El objetivo de este trabajo es presentar prácticas sobre cómo manejar y conservar un molino de bolas a escala de laboratorio, presentar un modelo de práctica experimental para determinar la tasa de trabajo en minerales y finalmente formas de adaptar el producto obtenido de la molienda a dos modelos de partículas distribución de tamaño basada en un experimento realizado en el equipo de estudio Las pautas para el uso del equipo y el procedimiento experimental son consistentes con la literatura u de posible ejecución, los resultados de los modelos de tamaño de partícula son comparables, siendo el modelo GGS el que mejor representa el producto granulométrico obtenido.

Palabras clave: Molino de bolas; Funcionamiento del equipo; Índice de trabajo; Análisis de partículas.

\section{Introdução}

A indústria mineral brasileira ao longo da última década registra um crescimento vigoroso graças as mudanças socioeconômicas e de infraestrutura que o Brasil tem vivenciado, embora em função da crise internacional a atividade mineral tenha sofrido redução em suas projeções o Brasil continua sendo um dos maiores do mundo em reservas minerais e exportação 
de minérios. O volume de exportações do setor mineral, em 2017 aumentou 31,2\% em relação ao ano de 2016, aproximadamente 13\% das exportações totais do Brasil e 30,5\% do saldo da balança comercial (Ibram, 2018).

Uma indústria de cominuição para manter sua competitividade de mercado necessita de um gerenciamento estratégico de operação e manutenção em seus equipamentos para que entreguem o melhor desempenho no sistema produtivo. Quando se tem o controle da manutenção é provável minimizar a indisponibilidade dos equipamentos aumentando a confiabilidade destes, a partir da eliminação de falhas inesperadas que podem comprometer a imagem da empresa, principalmente, se envolverem a segurança dos seus colaboradores e a do meio ambiente (Costa, 2013).

O moinho de bolas na indústria de cominuição é um equipamento de acabamento do processo, operando com uma menor faixa granulométrica em relação aos outros equipamentos. Seu ótimo funcionamento depende de condições perfeitas de operação, como: volume de enchimento do tambor, velocidade de rotação, exposição do equipamento ao ambiente e até gasto energético da moagem. Além das condições de operação é de profunda importância a manutenção do equipamento no que tange lubrificação de mancais, desgaste de peças, vibrações durante a operação, aquecimento de motor, estado das buchas e até a aparição de ferrugem.

É de fundamental importância a orientação especializada na operação de um moinho de bolas e a manutenção para que se mantenha a mantenabilidade do equipamento, sem perder sua confiabilidade. A pintura das peças metálicas que compõem o equipamento precedido de uma limpeza superficial para o aumento da ancoragem mecânica da tinta é um claro exemplo de cuidado e manutenção no assunto ferrugem, pois o agravamento da oxidação do metal pode ocasionar no surgimento de fendas indesejáveis (Pannoni, 2007) colocando em risco a integridade do equipamento e a segurança de seus operadores.

Além da operação e manutenção de um moinho, é preciso conhecer seu produto de saída do tambor, para isso, análises granulométricas se fazem necessárias para o conhecimento das propriedades físicas e morfológicas relacionadas às partículas. Além disso é muito importante a compreensão de fenômenos que regem determinadas operações unitárias (Cremasco, 2014).

O tamanho é um desses parâmetros, aonde a técnica de peneiramento se faz necessária relacionando-se a fração mássica das partículas retidas em uma série de peneiras padronizadas, dispostas organizadamente e de forma decrescente em relação aos diâmetros de abertura (Cremasco, 2014).

Desta forma o trabalho tem como objetivo facilitar e otimizar o uso do equipamento moinho de bolas com instruções de uso e cuidados, parâmetros e ferramentas para variações de regimes de moagem e um exemplo de como tratar os dados obtidos e como analisa-los.

\subsection{Parâmetros de Operação}

A velocidade de rotação do tambor interfere diretamente na trajetória dos corpos moedores do moinho. Até que a força centrífuga das bolas for maior que a força da gravidade as bolas permanecerão na trajetória circular, porém, quando a componente da gravidade que se opõem a força centrífuga for maior que a própria força centrífuga as bolas abandonam a trajetória circular e passam a traçar uma trajetória parabólica. A Figura 1 ilustra a transição da trajetória circular para a trajetória parabólica dos corpos moedores dentro do tambor de um moinho. 
Figura 1. Trajetória dos corpos moedores.

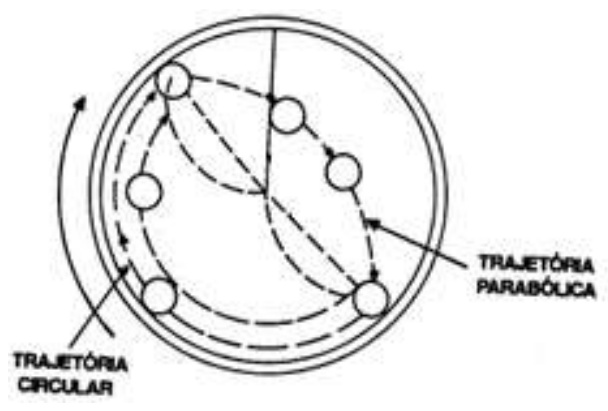

Fonte: Luz (2010).

À medida que a velocidade de rotação do moinho aumenta, chega um momento que o corpo moedor ficará preso na trajetória circular, preso a carcaça, pela ação da força centrífuga, durante uma volta completa do cilindro. Nessas condições não haverá qualquer realização de trabalho por parte do corpo moedor, logo, não havendo moagem na operação. A velocidade de rotação em que esse fenômeno ocorre é chamada de velocidade crítica do moinho.

Sempre que se refere a velocidade de rotação do moinho é sempre adotada em percentagem de sua velocidade crítica. Do ponto de vista operacional os moinhos são operados em velocidades de 50 a $90 \%$ da sua velocidade crítica e a escolha dessas é mediante ao tipo de produto de moagem que se quer obter. A velocidade crítica é calculada pela equação 1 :

$\mathrm{V}_{\mathrm{C}}=\frac{60}{2 \pi} \sqrt{\frac{\mathrm{g}}{\mathrm{R}-\mathrm{r}}}$

em que g é a aceleração da gravidade, $\mathrm{R}$ o raio do tambor do moinho e $\mathrm{r}$ o raio dos corpos moedores (bolas).

A velocidade de rotação do tambor tem total influência no regime de operação do moinho, o regime de moagem em catarata a velocidade do moinho carrega os corpos moedores até uma elevada posição e os mesmos caem sobre os outros corpos causando a fragmentação por impacto. Para explorar este regime é aconselhável um baixo fator de enchimento e o uso de corpos moedores maiores para aumentar a energia do meio moedor. Este regime é adequado para a fragmentação de material mais grosso evitando a produção de finos, este regime também acarreta no maior desgaste dos corpos moedores.

Diferente do regime em catarata que necessita de uma velocidade de rotação do tambor maior, o regime em cascata necessita de menor velocidade de rotação e um alto fator de enchimento que fazem com que os corpos moedores alcancem uma determinada altura e rolem sobre o meio composto de minério e os outros corpos moedores, praticamente não ocorrendo impacto, a moagem ocorre por abrasão e atrito. É indicado que se use corpos moedores menores e este regime é adequado para a obtenção de um produto final de granulometria fina. A Figura 2 ilustra como os corpos moedores agem dentro do tambor em diferentes regimes de moagem. 
Figura 2. Moagem em regime de catarata (a) e cascata (b).
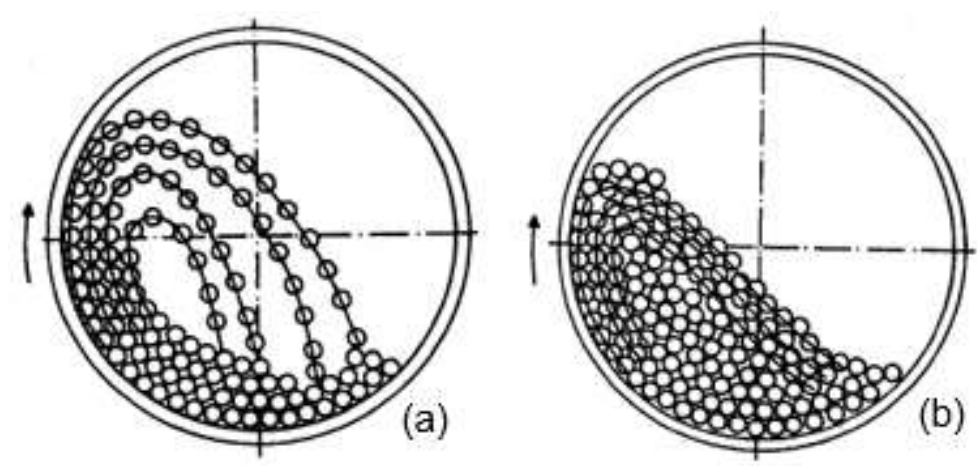

Fonte: Luz (2010).

O processo de moagem é influenciado diretamente pela distribuição de elementos moedores no interior do tambor, assim a abundância deles no meio moedor é um fator determinante para o rendimento do processo. A literatura diz que entre 50 á $55 \%$ do volume útil do moinho preenchido com a polpa a ser moída (corpos moedores e minério) é dita a condição ótima de operação. (Ribeiro, et al., 2001).

Diferente deste, outro parâmetro para calcular a quantidade de corpos moedores e bolas para a operação de moagem é através de uma relação massa-massa entre bolas e minério. Este parâmetro é mais superficial pois deve-se lembrar que diferentes tipos de corpos moedores possuem densidades diferentes, logo, uma relação dentro de um moinho de bolas, com bolas de alta alumina é dada como recomendada a de: $2,00 \mathrm{Kg}$ bolas $/ \mathrm{Kg}_{\text {material. }}$ (Bosa, et al., 2007). Já um moinho que usa esferas de vidro como elementos moedores a relação é de 4,50 Kg bolas $/ \mathrm{Kg}_{\text {material. }}$ (Rocha, et al., 2019).

O desgaste dos corpos moedores é inevitável, para minimizar este fenômeno a dureza do material escolhido para a moagem tem fundamental importância, a dureza deste deve ser menor que todo o meio de moagem, tambor e corpos moedores. Alguns equipamentos usam esferas de aço inoxidável ou alumina (Nos, 2011) e também vidro. Além de que quanto maior a diferença de dureza mais facilitada será a moagem. A tabela 1 indica a diferença de dureza entre os materiais que serão trabalhos, em dureza Mohs que é a resistência que um determinado mineral oferece ao risco e dureza Shore D que significa a resistência que um determinado mineral oferece ao impacto.

Tabela 1. Comparação das propriedades dos materiais.

\begin{tabular}{l|llll} 
Material & $\begin{array}{l}\text { Composição } \\
\text { Principal }\end{array}$ & $\begin{array}{l}\text { Dureza } \\
(\text { Mohs })\end{array}$ & $\begin{array}{l}\text { Dureza } \\
(\text { Shore D) }\end{array}$ & $\begin{array}{l}\text { Densidade } \\
\left(\mathrm{g} \mathrm{cm}^{-3}\right)\end{array}$ \\
\hline Vidro & Variável & $5,5-6$ & $60-75$ & $2,4-2,8$ \\
PVC & C, H & - & $65-85$ & $1,40-1,45$ \\
Carvão Mineral & C & $2,75-3$ & - & $1,6-1,9$ \\
& \multicolumn{2}{rl}{ Fonte: (Babisk, 2009 \& Brasken, 2002 \& Operaction, 2020) }
\end{tabular}

O tempo de moagem é um importante parâmetro de operação tanto na economia de energia do processo quanto na produção de finos que diminuem a eficiência do processo e acarreta em perdas do produto de moagem, por isso deve-se ter uma estimativa de tempo de moagem ideal. No moinho de bolas em questão cujo o tambor é de PVC e os corpos moedores são esferas de vidro, o tempo de moagem ideal é entre uma e duas horas. (Rocha, et al., 2019). 


\subsection{Manutenção e Corrosão}

A estrutura que compõem e segura o moinho muitas vezes é de ferro, aço ou aço-carbono, qualquer defeito ou problema nessa peça é crucial para o sustentamento do equipamento e seu funcionamento, por isso deve-se ter um cuidado detalhado além de conhecer seus possíveis riscos e futuros defeitos.

O fenômeno da corrosão, comumente ocorre em metais e ligas relativamente homogêneas expostas a ambientes também homogêneos. Este fenômeno é chamado de corrosão uniforme. O desgaste través da corrosão ocorre através de duas reações eletroquímicas simultâneas distribuídas uniformemente sobre a superfície do material: a reação anódica, a oxidação do metal (passagem do íon à solução) e a reação catódica que é a redução do oxidante presente no meio $\left(\mathrm{O}_{2}\right.$ dissolvido na atmosfera ou $\mathrm{H}^{+}$, entre outros). Um fator agravante da corrosão é a umidade relativa do ar, obviamente um ar mais úmido possui mais espécies oxidantes disponíveis para a reação catódica (Pannoni, 2007). A Figura 3 ilustra como a ferrugem avança sob uma superfície metálica ao longo do tempo.

Figura 3. Distribuição da ferrugem ao longo de uma peça metálica.
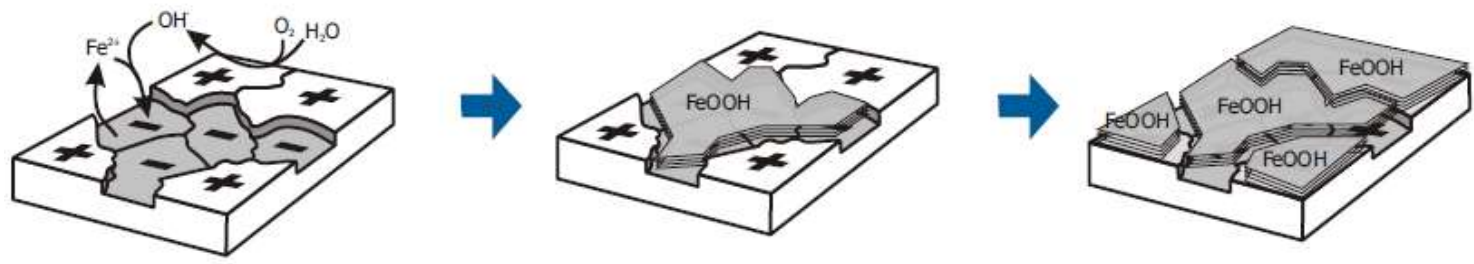

Fonte: Pannoni (2007).

Este processo de corrosão pode ser considerado um efeito dominó, pois a medida que a corrosão espalha na peça os agentes corrosivos presente no ambiente (oxidantes do ar) conseguem atingir novas camadas do metal exposto até comprometer estruturalmente todo o equipamento.

O método mais simples de proteção a corrosão é a pintura da superfície metálica previamente preparada em duas etapas: limpeza superficial e ancoragem mecânica. A primeira trata-se da remoção da superfície de matérias que possam impedir o contato direto da tinta com o aço, como pós diversos, gorduras, óleos, ferrugem, suor entre outros. A segunda etapa é basicamente o aumento da rugosidade superficial para proporcionar o aumento da superfície de contato entre o material e a tinta, auxiliando, dessa maneira, o aumento da aderência. O perfil de rugosidade do metal especificado está ligado à espessura da camada seca de tinta que se deseja aplicar.

Tintas acrílicas são tintas monocomponentes à base de solventes orgânicos ou de àgua, são indicadas para a pintura de acabamento, bastantes resistentes ao sol a finalidade desta também chamada tinta de fundo é promover a aderência do esquema ao substrato que contém pigmentos inibidores de corrosão, tintas acrílicas são utilizadas para a proteção dos aços estruturais (Pannoni, 2007).

\section{Energia no moinho / WI de Bond}

Toda a energia fornecida a um equipamento de cominuição como o moinho de bolas, ocorre o aproveitamento de no máximo $2 \%$ para a redução do minério alimentado no equipamento (Gomide, 1983). Portanto, essa área se configura em uma grande área para o desenvolvimento de pesquisas no ganho de energia.

O índice de trabalho (WI) indica numericamente, o total de energia em $\mathrm{kWh}$ por tonelada curta $(907 \mathrm{Kg})$ que é necessária para reduzir o minério, desde um tamanho teoricamente infinito até 80\% passante em $106 \mathrm{~m}$ (Figueira et al., 2004). Além de ser 
um importante parâmetro para o dimensionamento de um moinho cilíndrico este parâmetro torna-se possível calcular a energia necessária para moer o minério a determinada granulometria.

A energia necessária para fragmentar uma certa massa de minério homogêneo é estabelecida pela lei de Bond, esta, é expressada na equação 2 , onde:

$\mathrm{E}=10 * \mathrm{WI} *\left(\frac{1}{\sqrt{\mathrm{P}}}-\frac{1}{\sqrt{\mathrm{F}}}\right)$

Na equação acima, E representa a energia em kWh para moer uma tonelada curta de minério, WI índice de trabalho (work index), $\mathrm{P}$ abertura da peneira, em micrômetros $(\boldsymbol{\mu} \mathrm{m})$, através da qual passam $80 \%$ da massa do produto, $\mathrm{F}$ abertura da peneira, em micrômetros $(\boldsymbol{\mu} \mathrm{m})$, através da qual passam $80 \%$ da massa da alimentação.

Os ensaios para determinar o WI, em laboratório, devem ser conduzidos em um moinho padrão, usado para essa finalidade, seguindo o desenho esquemático mostrado pela figura 4 que ilustra um diagrama de circuito fechado.

Figura 4. Circuito fechado de moagem para o cálculo do WI.

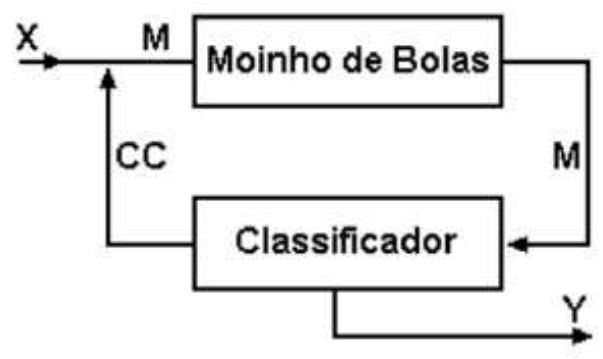

Fonte: Barbato (2007).

Na figura X é a alimentação nova (adicionada) da respectiva corrida, M é alimentação total (constante), Y o produto que neste processo é descartado e CC a carga circulante.

Ao longo do processo será necessário o cálculo e controle das rotações durantes das corridas de moagem, para isso a equação (3) será necessária:

$\mathrm{N}_{\mathrm{r}_{\mathrm{i}+1}}=\frac{\mathrm{A}_{\mathrm{ar}}-\mathrm{M}_{\mathrm{a}_{i+1}}}{\operatorname{Mob}_{\mathrm{i}}}$

Ao final das corridas, quando os parâmetros do método estiverem se alinhando com baixo erro, o cálculo do WI será dado através da equação (4):

$$
\mathrm{WI}=\frac{44,5}{(\mathrm{Am})^{0,28} *(\mathrm{Mob})^{0,82}} * \frac{1,1}{\frac{10}{\sqrt{\mathrm{P}}}-\frac{10}{\sqrt{\mathrm{A}}}}
$$

\subsection{Analise Granulométrica}

Para que seja feita a análise granulométrica deve-se realizar a separação dos minérios ou partículas em distintos grupos de acordo com seu tamanho. A separação é realizada em peneiras de arames que formam aberturas quadradas ou chamadas malhas sempre de um tamanho uniforme. (Medeiros \& Fernandes, 2001) 
Os dados obtidos na análise granulométrica são representados em forma de curvas onde a porcentagem que passa em cada peneira é colocada nas ordenadas e o diâmetro das partículas nas abcissas. A partir dessa curva, consegue-se obter diâmetros característicos como $\mathrm{d}_{20}, \mathrm{~d}_{50}, \mathrm{~d}_{80}$. São dados importantes tanto para o projeto tanto para a operação do equipamento.

Os resultados obtidos podem ser generalizados por expressões matemáticas chamadas de funções de distribuições de tamanho, estas equações relacionam o tamanho da partícula com uma percentagem em peso, resumidamente é o acumulado retido ou passante (Signor, et al.,2017) alguns modelos de equações como o GGS e o RRB são ilustrados nas equações (5) e (6) respectivamente:

$$
\mathrm{X}=\left(\frac{\mathrm{D}}{\mathrm{k}}\right)^{\mathrm{m}}
$$

$$
X=1-e^{-\left(\frac{D}{D^{r}}\right)^{n}}
$$

em que, $\mathrm{k}$ e m são os parâmetros a serem ajustados aos dados experimentais oriundos da moagem seguido de peneiramento para o GGS e os parâmetros de RRB são n e D'.

\section{Metodologia}

Este trabalho pode ser divido em duas partes, sendo a primeira uma pesquisa qualitativa com coleta direta de dados (Pereira, et al., 2018) onde pesquisou-se em bibliografias importantes além de cruzar as experiências já praticadas no equipamento para se determinar a melhor faixa de operação para o equipamento preservando seu estado de conservação, também se pesquisou especificamente um método laboratorial para a determinação do work index de materiais que se adequam a faixa de dureza que o moinho pode operar. A segunda parte compõe a parte quantitativa, da pesquisa tratando-se de uma análise de dados e construção de hipóteses (Köche, 2011) de um produto de moagem obtido do mesmo equipamento, onde obteve-se os dados de operação anteriormente citados, para determinar-se o melhor modelo de análise granulométrica que descreve o produto obtido.

\subsection{Operação e manutenção}

Traçou-se diretrizes adequadas de como montar, ligar e manusear o equipamento, bem como detalhes de como conservar a ferragem do equipamento, seus elementos moedores, motor, tambor e sistema controlador de velocidade.

Indicou-se a respeito da velocidade de operação do moinho, expondo diferentes parâmetros de operação utilizado no equipamento e em literatura, expondo os pontos positivos e negativos do seu aumento e também da sua diminuição. Para auxiliar e otimizar o controle, mostrou-se a construção de uma curva de calibração do equipamento para que se alinhe o controle da velocidade do controlador aos parâmetros de bibliografia na unidade de rotações por minuto.

Mostrou-se os dois parâmetros de operação a respeito do enchimento do tambor mostrando que essa variável é calculada pela proporção mássica entre minério e corpos moedores sendo levada em conta a densidade do material e também a porcentagem de enchimento do tambor, sendo a proporção mássica através de uma balança e a porcentagem de enchimento através de uma fita métrica (trena) usando como referência à altura de coluna do meio moedor (minério somado aos corpos moedores) em função da altura do tambor. 


\subsection{Cálculo do Work Index}

Indicou-se dezenove passos afim de criar-se um circuito fechado de moagem com reciclo e carga circulante, que após repetidas corridas com número de rotações contados e calculados combinados com o peneiramento em $\mathrm{A}_{\mathrm{M}}$ para separar o overflow que volta ao moinho e o underflow que é descartado obtêm-se os valores de mobilidade (Mob). Ao longo da prática preenche-se uma tabela de onze colunas e obtém-se o work index do minério trabalhado, com esse parâmetro é possível calcular a energia desprendida ao longo de uma moagem no equipamento utilizado. A Tabela 2 abaixo é um exemplo de como deve ser efetuado o tratamento de dados no cálculo do índice de trabalho de um minério.

Tabela 2. Exemplificação da tabela referente ao cálculo do índice de trabalho.

\begin{tabular}{|l|l|l|l|l|l|l|l|l|l|l|}
\hline Col. 1 & Col. 2 & Col. 3 & Col. 4 & Col. 5 & Col. 6 & Col. 7 & Col. 8 & Col. 9 & Col. 10 & Col. 11 \\
\hline
\end{tabular}

Fonte: Autores.

Coluna 1: número da corrida

Coluna 2: número de rotações que após a primeira corrida, com número fixo de rotações, utiliza-se da equação 7 :

$$
\frac{\mathrm{A}_{\mathrm{ar}}-\left(3^{\circ} \text { Coluna }\right)}{\left(8^{\circ} \text { Coluna }\right)_{\mathrm{i}-1}}
$$

Coluna 3: Massa passante inicial antes de cada corrida $\left(\mathrm{M}_{\mathrm{ai}}\right)$

Coluna 4: Massa retida na peneira $\mathrm{A}_{\mathrm{M}}$

Coluna 5: Massa passante em $\mathrm{A}_{\mathrm{M}}\left(\mathrm{M}_{\mathrm{Pi}}\right)$

Coluna 6: Passante líquido dos ciclos em massa que é efetuado pela seguinte subtração:

$\left(5^{\circ}\right.$ Coluna $)-\left(3^{\circ}\right.$ Coluna $)$

Coluna 7: Desvio, calculado pela equação 9:

( $5^{\circ}$ Coluna $)$ - (Passante alimentação em $\left.\mathrm{A}_{\mathrm{ar}}\right)$

Coluna 8: Mobilidade, calculada pela equação 10:

$\frac{\left(6^{\circ} \text { Coluna }\right)}{\left(2^{\circ} \text { Coluna }\right)}$

Coluna 9: Média dos 3 últimos valores de mobilidade:

$\underline{\text { (Soma das três mobilidades) }}$ 3

Coluna 10: $5 \%$ da média das mobilidades calculada: 
$\left(9^{\circ}\right.$ Coluna $) * 0,05$

Coluna 11: Diferença entre os três últimos valores de mobilidade:

(Maior $8^{\circ}$ Coluna $)-\left(\right.$ Menor $8^{\circ}$ Coluna $)$

Materiais Utilizados para o cálculo do WI

○ Peneira $A_{M}$ de $125 \mu \mathrm{m}$

- Peneira de $3 \mathrm{~mm}$

○ Proveta $1000 \mathrm{ml}$

- Balança

○ Moinho de Bolas

\subsection{Modelos Granulométricos}

$\mathrm{Na}$ aplicação dos modelos granulométricos tratou-se os dados de acordo com o modelo GGS em que se calculou o logaritmo do Diâmetro médio das peneiras $\ln (\mathrm{Di})$ e o logaritmo da fração acumulada $\ln (\mathrm{X})$. A partir desses dados plotou-se o gráfico a traçou-se a reta de tendência para aproximação. No modelo RRB o gráfico contém os mesmos dados de ln(Di) no eixo das ordenadas e $\ln \{\ln [1 /(1-x i)]\}$ no eixo da abscissa, onde $\mathrm{x}_{\mathrm{i}}$ é a fração mássica em cada peneira. Traçada as duas curvas e com as duas retas de tendências, avalia-se qual o melhor modelo dentre os dois para representar através de uma equação o produto da moagem que foi efetuada no primeiro experimento do qual este equipamento foi submetido.

\section{Resultados e Discussão}

\subsection{Procedimentos necessários para funcionamento do moinho}

Antes da moagem começar, a montagem do equipamento é de extrema importância. Algumas práticas e procedimentos se fazem necessários para preservar a integridade do equipamento e sua funcionalidade.

O local de funcionamento do moinho deve ser amplo e espaçoso, longe da passagem de pessoas de modo que nada esbarre ou atrapalhe o funcionamento do equipamento. É importante que o moinho esteja na sombra, pois seu motor naturalmente já sofre aquecimento em função de seu funcionamento, somados com a luz solar intensa e duradoura de uma corrida de moagem não é aconselhável, pelo motor ser uma peça fundamental no equipamento e seu reparo muito custoso.

Na montagem do equipamento é importante posicionar borracha como apoio nos quatro pés do moinho, o funcionamento constante do tambor gera muita vibração, a borracha de apoio irá minimizar os danos causados pela vibração como afrouxamento de parafusos do moinho ou até mesmo reposicionamento do moinho inteiro.

No controlador do motor, controlador de motor de esteira, utiliza-se de uma pilha alcalina tamanho AA deve-se checar se ela está em condições de uso. O controlador possui duas importantes funções das três disponíveis no visor: velocidade de rotação e tempo de funcionamento. A primeira é importante criar-se uma curva de calibração para se ter a real noção da velocidade c de funcionamento do moinho e sua velocidade crítica de rotação.

\subsection{Curva de calibração}

A velocidade indicada pelo conjunto sensor e controlador, acredita-se em $\mathrm{km} / \mathrm{h}$, dificilmente deve superar a grandeza de 8.0 a 10.0. Para que saibamos o real valor da velocidade de rotação em RPM do tambor deve-se utilizar o cálculo da velocidade crítica como abaixo: 


$$
\begin{gathered}
\mathrm{V}_{\mathrm{C}}=\frac{60}{2 \pi} \sqrt{\frac{981,0}{15-0,9}}=79,65 \mathrm{RPM} \\
\frac{79,65}{1} * \frac{\text { Rotações }}{\text { Minuto }} \frac{1}{60} * \frac{\text { Minuto }}{\text { Segundos }} * \frac{2 \pi * 0,15}{1} * \frac{\text { Metros }}{\text { Rotações }}=4,5 \frac{\text { Kilometros }}{\text { hora }}
\end{gathered}
$$

A velocidade crítica teórica calculada acima diz respeito a distância do centro do tambor até o sensor do equipamento de 15 centímetros, deve-se levar em consideração seu valor real. A curva de calibração será construída a partir da observação do número de rotações em um minuto de operação, anotado esse valor de RPM (rotações por minuto) compara-se com o valor indicado no visor do controlador. Indica-se que faça para vários valores até que se construa um gráfico de RPM real versus velocidade marcada em $\mathrm{km} / \mathrm{h}$.

\subsection{Velocidade Critica}

A velocidade utilizada no primeiro trabalho deste moinho marcava no visor do controlador de 8.0 a 10.0 na moagem de rocha fosfática e apresentou uma redução de 96,95\% do tamanho inicial, se mostrando muito eficaz (Rocha, et al., 2019).

Em contrapartida a literatura diz que a velocidade indicada para moagem é cerca de $70 \%$ até $85 \%$ da velocidade crítica $\mathrm{V}_{\mathrm{C}}$ (De Paula, et al., 2014) em RPM aproximadamente 55 a 64. Uma moagem com a percentagem correta da velocidade crítica segundo literatura sendo respeitada ocasiona em um produto bem moído com pouca massa de finos e ultrafinos (Nascimento. 2013) e um menor desgaste dos corpos moedores devido ao regime de cascata de moagem. Quando maior a velocidade de rotação mais o equipamento se aproxima de um regime de moagem em catarata, o aumento cauteloso da velocidade de moagem ocasiona na diminuição do tempo de moagem necessário para a obtenção de um produto devidamente bem moído em um curto período de tempo sem exageros no aumento pois se muito alta a trajetória dos corpos moedores deixará de ser parabólica e nesse estado não há moagem.

\subsection{Enchimento do Vaso}

Este fundamental fator de operação diz respeito muito sobre seu processo de moagem, o meio de moagem engloba o minério em questão e os corpos moedores, assim, abordaremos o enchimento do vaso de duas maneiras. Sabendo que o kit deste moinho possui 1200 esferas de vidro de $18 \mathrm{~mm}$ de diâmetro a primeira relação será mássica, em que é adotada uma proporção massa-massa para minério e corpos moedores. No primeiro trabalho realizado neste moinho foi adotada a relação 1,0:4,5 (Rocha, et al., 2019) entre massa de material e massa de bolas respectivamente, na literatura diz-se usar uma relação de 1,8:2,0 entre massa de material e massa de bolas respectivamente, porém são considerados esferas de aço ou porcelana fato que a densidade do material muda totalmente essa percepção de proporção mássica. Por isso é de extrema importância abordar de uma segunda maneira como encher o vaso do moinho de bolas, pelo parâmetro volumétrico em que o meio moedor ocupa de $20 \%$ a $40 \%$ do volume total do vaso. No primeiro trabalho deste equipamento foi utilizado um volume de enchimento de 30\%, cerca de 12 centímetros de altura do tambor do moinho (Rocha et, al., 2019). Portanto para se trabalhar no equipamento deve-se atingir uma boa relação mássica combinado com um fator de enchimento sem exageros do moinho para se obter um meio de moagem que favoreça o bom desempenho do equipamento em um curto período de tempo.

\subsection{Cálculo do WI (Work Index)}

A seguir são determinados 19 passos necessários para a obtenção do valor do índice de trabalho de um minério (WI) através de um moinho laboratorial, a tabela a ser preenchida está no anexo deste trabalho. 
Passo 1. Alimentação previamente britada com $100 \%$ passante em $3,00 \mathrm{~mm}$

Passo 2. Análise granulométrica da alimentação

Passo 3. Determinar (A) a abertura da peneira onde existe $80 \%$ de passante do material

Passo 4. De toda a a amostra de alimentação, encher compactando uma proveta graduada de $1000 \mathrm{~mL}$, completar o volume até $700 \mathrm{~mL}$ pesar este material, o valor será (M) a massa da alimentação em gramas

Passo 5. Calcular $A_{a r}=M / 3,5$, é a massa da alimentação que deveria ser acrescentada quando em regime estacionário, a qual a carga circulante deve ser de $250 \%$

Passo 6. Determinar a abertura da malha de classificação do ensaio $A_{m}=150 \mu \mathrm{m}$ essa abertura deverá ser próxima àquela que fechará o circuito de moagem

Passo 7. Carregar o moinho com a carga de bolas e o material da proveta contido. Para o primeiro ciclo, moer o material por um número definido de rotações, por exemplo: 150 rotações.

Passo 8. Por peneiramento determinar a massa passante na peneira $A_{m}=150 \mu \mathrm{m}$ esse valor em gramas será $\left(\mathrm{M}_{\mathrm{A} 1} 3^{\circ}\right.$ Coluna) e pode ser estimado diretamente da análise granulométrica do material inicial

Passo 9. Após a primeira corrida o moinho deve ser descarregado e o material todo peneirado em $\left(A_{M}\right)$. Determinara a massa retida (4 $4^{\circ}$ coluna). A massa passante $\left(\mathrm{M}_{\mathrm{P}} 5^{\circ}\right.$ coluna) é calculada pela diferença. A massa retida será a alimentação da próxima corrida e a massa passante é descartada (exceto no último ciclo)

Passo 10. Subtrair ( $\mathrm{M}_{\mathrm{A}} 3^{\circ}$ coluna) de ( $\mathrm{M}_{\mathrm{P}} 5^{\circ}$ coluna). Este valor será o passante líquido gerado no determinado ciclo ( $6^{\circ}$ coluna).

Passo 11. Recompor a nova alimentação que será composta pela ( $\mathrm{M}_{\mathrm{P}} 5^{\circ}$ coluna que é a massa retida da corrida anterior) mais a massa de amostra inicial $\left(\mathrm{A}_{\mathrm{ar}}=\mathrm{M} / 3,5\right)$ para a próxima corrida

Passo 12. Com a nova massa inicial pronta, peneirar toda essa massa em $A_{M}$ para determinar a ( $3^{\circ}$ coluna) com ( $\left.M_{A i+1}\right)$

Passo 13. A massa passante de $\left(A_{\text {ar }}\right)$ que passou na peneira $\left(A_{M}\right)$ no passo 12 é usada no cáclulo do desvio ( $7^{\circ}$ coluna), onde nesse cálculo é feita a seguinte subtração: ( $5^{\circ}$ coluna, passante do produto da corrida 1$)$ menos (passante da alimentação da corrida 2)

Passo 14. O cálculo da ( $8^{\circ}$ coluna) mobilidade é feito dividindo o passante líquido ( $6^{\circ}$ coluna) por número de cotações aplicado na corrida ( $2^{\circ}$ coluna), lembrando que a primeira corrida o número de rotações foi determinado anteriormente.

Passo 15. Carregar novamente o moinho e agora calcular o novo número de rotações que será usado na próxima corrida $\left(\mathrm{N}_{\mathrm{i}+1}\right)$, usando:

$$
N_{r_{i+1}}=\frac{A_{a r}-M a_{i+1}}{M o b_{i}} \text { ou } N_{r_{i}}=\frac{A_{a r}-M a_{i}}{M o b_{i-1}}
$$

Passo 16. Proceder a moagem com o número de rotações calculado no passo 15

Passo 17. Repetir as operações descritas nos passos 9 á 16

Passo 18. Prosseguir o número de ciclos até que os valores de mobilidade ( $8^{\circ}$ coluna) atinjam o equilíbrio ou invertam a tendência de crescimento em três ciclos. A verificação desse equilíbrio é feita extraindo-se a média aritmética dos três últimos valores de mobilidade $\left(9^{\circ}\right.$ coluna) não devendo a diferença entra o maior e o menor valor $\left(11^{\circ}\right.$ coluna) ser superior a $5 \%$ em relação ao valor médio ( $10^{\circ}$ coluna)

Passo 19. Uma vez alcançado o equilíbrio, proceder a análise granulométrica no produto final da última corrida para se adquirir o calor de P (abertura da peneira onde 80\% da massa do produto é passante), obtém-se A e P por interpolação no gráfico de análise granulométrica, e por fim, calcula-se WI de acordo com a equação 15:

$$
\mathrm{WI}=\frac{44,5}{(\mathrm{Am})^{0,28} *(\mathrm{Mob})^{0,82}} * \frac{1,1}{\frac{10}{\sqrt{\mathrm{P}}}-\frac{10}{\sqrt{\mathrm{A}}}}
$$




\subsection{Modelos Granulométricos}

Obteve-se os dados de um dos testes de moagem que o moinho foi submetido que é indicado na Tabela 3:

Tabela 3. Ajustes do produto de moagem para o modelo GGS

\begin{tabular}{c|ccccc} 
Diâmetro Médio Peneiras (Di) & Massa Retida & Fração Mássica (xi) & Fração Acumulada (Xi) & $\ln (\mathrm{Xi})$ & $\ln (\mathrm{Di})$ \\
\hline 250 & 0,9750 & 0,4896 & 0,5104 & $-0,6725$ & 5,5214 \\
187,5000 & 0,4670 & 0,2344 & 0,2760 & $-1,2872$ & 5,2241 \\
100 & 0,3230 & 0,1619 & 0,1142 & $-2,1701$ & 4,6051 \\
64 & 0,2070 & 0,1040 & 0,0101 & $-4,5904$ & 4,1588 \\
45,5000 & 0,0200 & 0,0101 & 0,0000 & & 3,8177 \\
Fundo & 0,0000 & & & & \\
TOTAL & 1,992 & 1,0000 & 0,9108 & &
\end{tabular}

Fonte: Autores.

A partir desses dados plotou-se o gráfico de $\ln (\mathrm{Xi})$ pelo $\ln (\mathrm{Di})$ para obtermos o gráfico do modelo granulométrico GGS para esta moagem. A Figura 5 ilustra a curva obtida:

Figura 5. Modelo Granulométrico GGS.

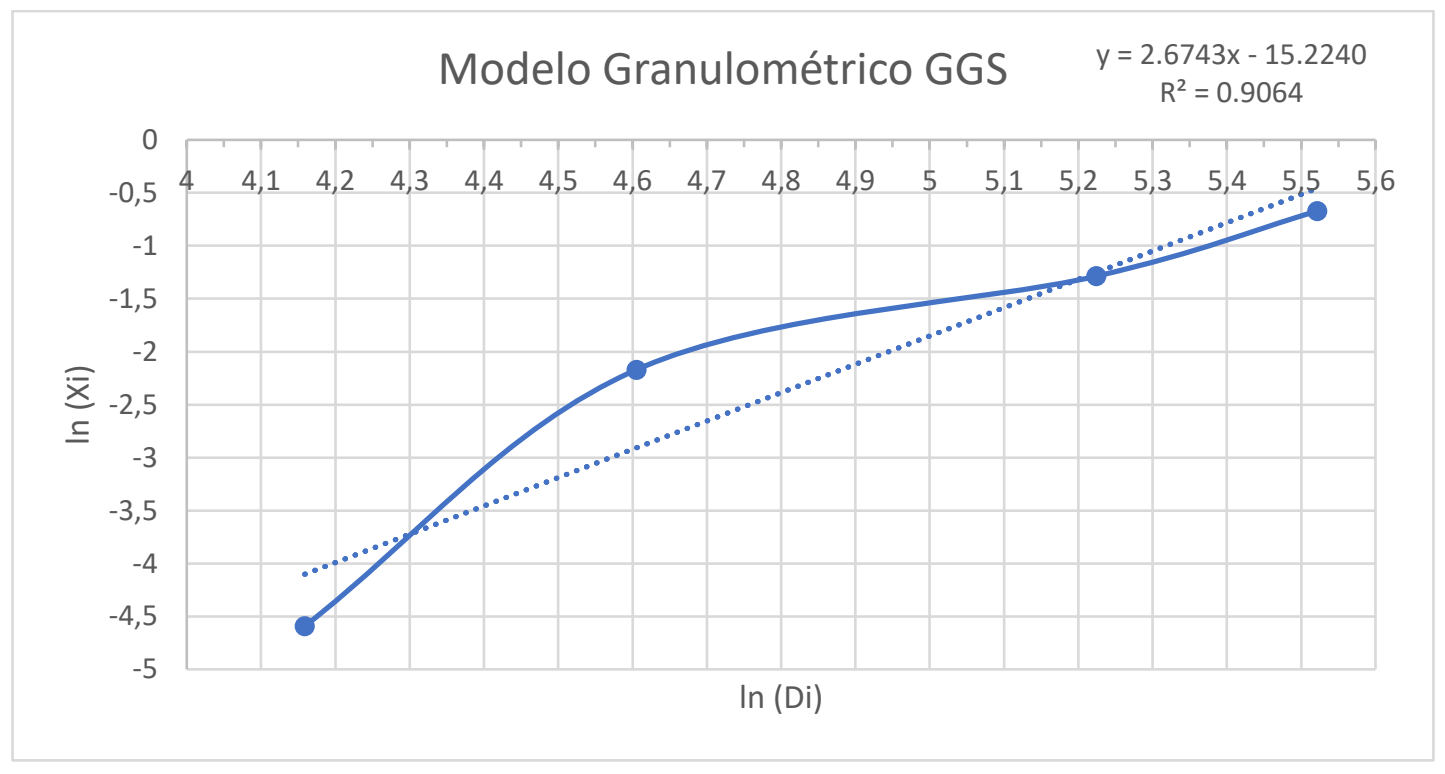

Fonte: Autores.

A partir da equação de reta obtida pelo software Excel que é de y $=2,6743 x-15,2240$ conseguimos calcular os fatores $\mathrm{m}=2,6743$ e $\mathrm{K}=296,6900$, logo a equação que modela essa distribuição granulométrica com $\mathrm{R}^{2}=0,9064$ é:

$X=\left(\frac{D}{296,6900}\right)^{2,6743}$

A título de comparação é conveniente aplicarmos outro modelo granulométrico, desta vez o RRB, por isso plotamos os mesmos dados de moagem agora com os parâmetros ajustados para este segundo modelo, a Tabela 4 indica os dados utilizados: 
Tabela 4: Ajustes do produto de moagem para o modelo RRB.

Diâmetro Médio Peneiras (Di) Massa Retida Fração Mássica (xi) Fração Acumulada (Xi) ln (Xi) $\ln \left(\ln \left(\frac{1}{1-\mathrm{x}_{\mathrm{i}}}\right)\right)$

\begin{tabular}{c|ccccc}
\hline 250 & 0,9750 & 0,4896 & 0,5104 & $-0,6725$ & 5,5214 \\
187,5000 & 0,4670 & 0,2344 & 0,2760 & $-1,2872$ & 5,2241 \\
100 & 0,3230 & 0,1619 & 0,1142 & $-2,1701$ & 4,6051 \\
64 & 0,2070 & 0,1040 & 0,0101 & $-4,5904$ & 4,1588 \\
45,5000 & 0,0200 & 0,0101 & 0,0000 & 3,8177 \\
Fundo & 0,0000 & & & \\
TOTAL & 1,992 & 1,0000 & 0,9108 &
\end{tabular}

Fonte: Autores.

O gráfico justamente com a reta de aproximação e sua equação foram plotados abaixo para o modelo granulométrico RRB, como é indicado através da Figura 6:

Figura 6. Modelo Granulométrico RRB.

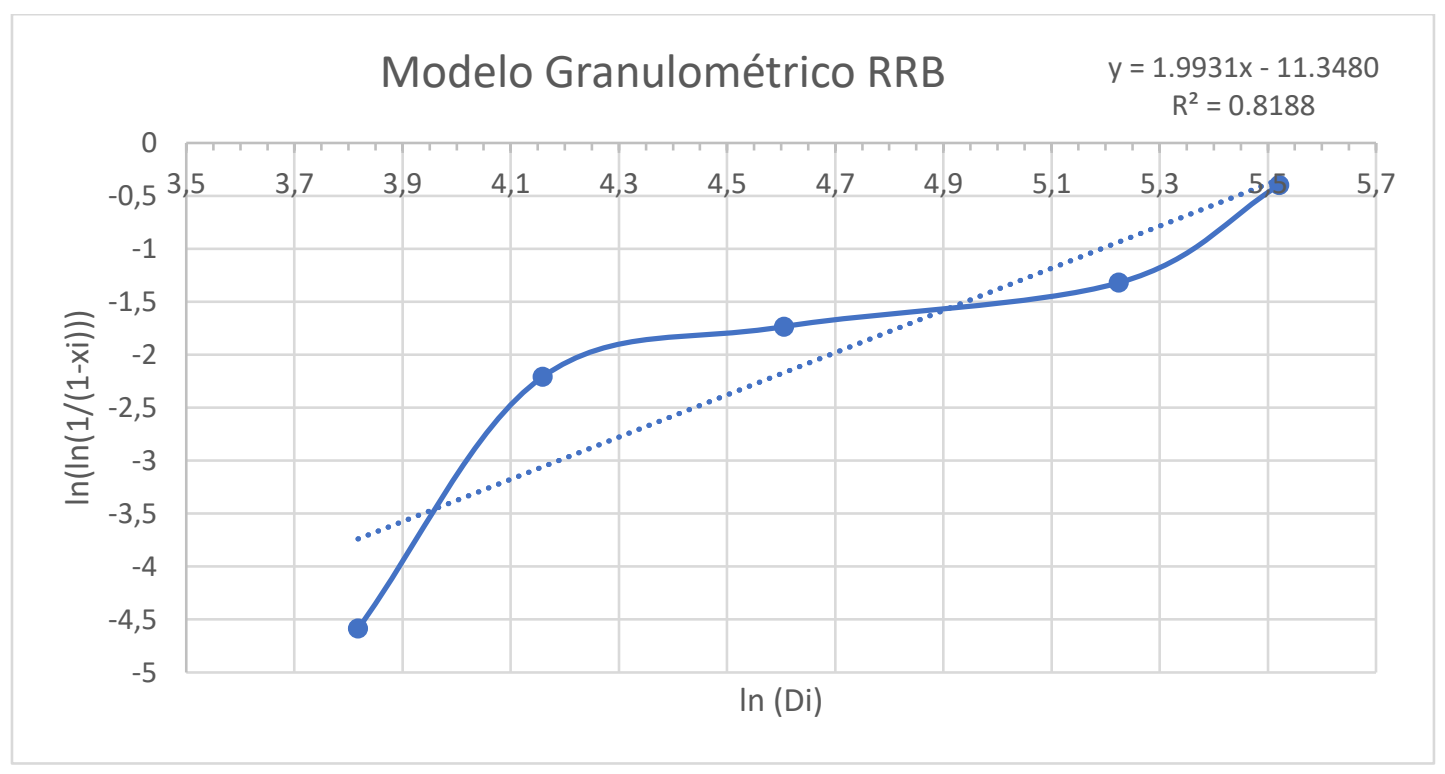

Fonte: Autores.

Através da equação obtida de $\mathrm{y}=1,9931 \mathrm{x}-11,3480$ obtemos os parâmetros do modelo que são $\mathrm{n}=1,9931$ e D' = 296,9700 com o $\mathrm{R}^{2}=0,8188$ a equação que representa esta distribuição granulométrica através do modelo RRB é:

$$
\mathrm{X}=1-\mathrm{e}^{-\left(\frac{\mathrm{D}}{296,9700}\right)^{1,9981}}
$$

Obtidos os dois métodos podemos destacar, através do valor de $\mathrm{R}^{2}$ que mais se aproxima de 1 , que o modelo GGS se enquadra melhor e sua equação representa com mais fidelidade a distribuição granulométrica deste produto de moagem exposto. 


\section{Considerações Finais}

O objetivo deste trabalho de indicar as melhores práticas e passos para se trabalhar com o equipamento, sugerir uma atividade no moinho e também indicar como se tratar os resultados obtidos do equipamento foi alcançado. O primeiro item indicando os parâmetros de operação que melhor encaixou ao equipamento, com métodos e variáveis já usadas e bem sucedidas no moinho. O segundo item guiando de acordo com a literatura uma prática de moagem afim de calcular o índice de trabalho de qualquer minério dentro da faixa de dureza que o moinho opera, com passos bem claros e bem explicados de modo que se atinja o objetivo do trabalho. $\mathrm{O}$ terceiro e último item estudado apresentando bons resultados, com um modelo granulométrico representativo do produto obtido da moagem bem coeso com os dados apresentando um valor de $\mathrm{R}^{2}$ igual á 0,9064.

O presente trabalho deixa como sugestão para futuras pesquisas a aplicação do método experimental para o cálculo do work index utilizando dos parâmetros de operação mostrados neste trabalho.

\section{Referências}

Babisk, M. P. (2009). Desenvolvimento de vidros sodo-cálcicos a partir deresíduos de rochas ornamentais. [Mestrado em Ciências dos Materiais]. Instituto Militar de Engenharia.

Barbato, C. N. \& Sampaio, J. A. (2007) Determinação Experimental do Índice de Trabalho (WI) Apostila de Tratamento de Minérios: Práticas Laboratoriais: CETEM/MCTI. 179-189.

Bosa, A. \& Ferro, A. \& Wanderlind, A. \& Pasini, D. \& Patrício, M. \& Tassi, R. \& Modesto, C. Noni, A. \& Cargnin, M. (2007). Influência do Resíduo in natura das Matérias-primas, Carga de Bolas e Resíduo Final no Tempo de Moagem via Úmida em Moinho de Bolas. Cerâmica Industrial. 12.

Braskem. (2002). Propriedades de referência dos compostos de PVC. Boletim Técnico, número 03 PVC.

Costa, M. A. (2013) Gestão estratégica da manutenção: uma oportunidade para melhorar o resultado operacional. [Trabalho de Conclusão de Curso em Engenharia de Produção]. Universidade Federal de Juiz de Fora. Juiz de Fora.

Cremasco, M. A. (2014) Operações Unitárias em Sistemas Particulados e Fluidomecânicos. Editora Blücher.

De Paula, L. \& Alves, A. C. A. \& Heden C. S. \& Ribeiro, E. A. \& Madurro, A. G. B. \& Madurro, J. M. (2014). Diretrizes para a construção de um moinho de bolas para a moagem de sólidos em laboratórios. Química Nova, 37(4).

Figueira, H. V. O. \& Almeida, S. L. M. \& Luz, A. B. (2004). Cominuição: Tratamento de Minérios. CETEM/MCT, (4a ed.), $113-182$.

Gomide, R. (1983). Operações Unitárias: Operações com Sistemas Granulares. Edição do Autor, 10 Volume.

Ibram. (2018). Economia mineral - Brasil. Portal da Mineração. Brasília: IBRAM (Instituto Brasileiro de Mineração. Economia Mineral do Brasil. http://portaldamineracao.com.br/wp-content/uploads/2018/08/economia-mineral-brasil-set2018.pdf.

Koche, J. C. (2011). Fundamentos de metodologia científica. Vozes. 5.4

Luz, A. B. \& Sampaio, J. A. França, S. C. A. (2010). Tratamento de Minérios. Centro de Tecnologia Mineral. CETEM. (5a ed.).

Nascimento, D. V. (2013). Análise de danimâmica de carga moedora nos moinhos de bolas. [Mestrado em Engenharia Metalúrgica e de Minas]. Universidade Federal de Minas Gerais.

Nos, G. (2011). Projeto de produtos:moinho de bolas de baixo custo. Lajeado, Rio Grande do Sul.

Operaction. (2020). Densidade dos materiais. Website da Operation. Especializada em Equipamentos de Construções. Terraplanagemwww.operaction.com.brhttp://www.operaction.com.br/densidade-dos-materiais.

Pannoni, F. D. (2007). Princípios da proteção de estruturas metálicas em situação de corosão e incêndio. Coletânia do uso do aço. (4a ed.).

Pereira, A. S. et al. (2018). Metodologia da pesquisa científica. UFSM.

Ribeiro, M. \& Abramtes. J. (2001). Moagem em Moinho de Bolas: Estudo de algumas Variáveis e Otimização Energética do Processo. Cerâmica Industrial. 6, $7-11$.

Rocha, B. C., Teixeira, G. F., Tromdade. R. S., Arruda, E. B. \& Souza, D. L. (2020). Design, construction and operation of a ball mill on a pilot scale. Research, Society and Development. 9(8), e118985149. https://rsd.unifei.edu.br/index.php/rsd/article/view/5149

Signor, J.P.F. \& Pereira, G. G. \& Alves, L. F. P. Bonfim, E. R. Matos, J. (2017). Estudo da análise granulométrica da alimentação do moinho e do overflow de ciclones. 